Article

\title{
Neutrophil to Lymphocyte Ratio (NLR) as an Easily Accessible Parameter for Monitoring Tacrolimus Overdose after Heart Transplantation-Experimental Study
}

\author{
Tomasz Urbanowicz ${ }^{1, *(\mathbb{D})}$, Anna Olasińska-Wiśniewska ${ }^{1}\left(\mathbb{D}\right.$, Michał Michalak $^{2}{ }^{\mathbb{D}}$, Michał Rodzki ${ }^{1}$, \\ Anna Witkowska ${ }^{1}{ }^{1}$, Ewa Straburzyńska-Migaj ${ }^{3}$, Bartłomiej Perek ${ }^{1}\left(\mathbb{D}\right.$ and Marek Jemielity ${ }^{1}$ \\ 1 Cardiac Surgery and Transplantology Department, Poznan University of Medical Sciences, \\ 61-848 Poznan, Poland; anna.olasinska@poczta.onet.pl (A.O.-W.); michal.rodzki@skpp.edu.pl (M.R.); \\ anna.witkowska@skpp.edu.pl (A.W.); bperek@ump.edu.pl (B.P.); mjemielity@poczta.onet.pl (M.J.) \\ 2 Department of Computer Science and Statistics, Poznan University of Medical Sciences, \\ 61-848 Poznan, Poland; michal@ump.edu.pl \\ 3 1st Department of Cardiology, Poznan University of Medical Sciences, 61-848 Poznan, Poland; \\ ewa.straburzynska-migaj@skpp.edu.pl \\ * Correspondence: Tomasz.urbanowicz@skpp.edu.pl; Tel.: +48-605-552-551 or +48-618-549-210
}

check for updates

Citation: Urbanowicz, T.; Olasińska-Wiśniewska, A.; Michalak, M.; Rodzki, M.; Witkowska, A.; Straburzyńska-Migaj, E.; Perek, B.; Jemielity, M. Neutrophil to Lymphocyte Ratio (NLR) as an Easily Accessible Parameter for Monitoring Tacrolimus Overdose after Heart Transplantation-Experimental Study. Diagnostics 2022, 12, 37. https://doi.org/10.3390/ diagnostics12010037

Academic Editor: Gino

Seravalle Seravalle

Received: 19 November 2021

Accepted: 22 December 2021

Published: 24 December 2021

Publisher's Note: MDPI stays neutral with regard to jurisdictional claims in published maps and institutional affiliations.

Copyright: (C) 2021 by the authors. Licensee MDPI, Basel, Switzerland. This article is an open access article distributed under the terms and conditions of the Creative Commons Attribution (CC BY) license (https:// creativecommons.org/licenses/by/ $4.0 /)$.

\begin{abstract}
Background: The combination of candidate selection, immunosuppressive therapy adjustment, and scrutinous monitoring is a cornerstone for optimizing long-term survival after a heart transplant. Neutrophil-to-lymphocyte ratio (NLR) is a simple marker of inflammatory reactions activation and may play a clinical role as a predictive marker in oncological and cardiovascular diseases. The aim of the study was to find simple hematologic indices available from whole blood count to help in immunosuppressive therapy monitoring. (2) Methods: Thirty patients (23 men and 7 women) with a mean age of $43+/-13$ years who had undergone orthotopic heart transplantation were enrolled into the study. The blood samples for whole blood count and Tacrolimus level were collected during outpatient visits in heart transplant recipients every two months for 18 months after first year post transplantation. (3) Results: There was a significant correlation between Tacrolimus overdose $(>15 \mathrm{ng} / \mathrm{mL}$ ) and NLR (Spearman's rho 0.99, $p<0.001)$ and mean platelet volume (Spearman's rho $0.989, p<0.001)$. The ROC analysis for NLR above 3.62 showed predictive properties for Tacrolimus overdose (over $15 \mathrm{ng} / \mathrm{mL}$ ) (AUC $=0.633, p=0.008$ ) with a sensitivity of $50 \%$ and specificity of $83.73 \%$. (4) Conclusions: Our results suggest that NLR above 3.62 may be regarded as a simple indicator of tacrolimus overdose.
\end{abstract}

Keywords: heart transplantation; tacrolimus; NLR; MPV; drug overdose

\section{Introduction}

Advanced heart failure involves symptoms affecting daily life activity, followed by high mortality, and it remains a major clinical and public health problem [1]. These patients may be treated, ultimately, with heart transplantation, characterized by 1-year survival approaching 80 to $90 \%$ [2]. The combination of candidate selection, immunosuppressive therapy adjustment and scrutinous monitoring is a cornerstone for optimizing long-term survival. Contemporary therapeutical protocols are based on calcineurin inhibitors [3].

A review performed by Hussain et al. presented a wide variety of problems influencing adherence to immunosuppression in transplant patients and concluded that there were modifiable factors to address to create improvements [4].

We believe that incorporating simple laboratory markers indicating the serum level disturbances in patients taking immunosuppressive drugs should be regarded as of primary value. Notably, drug level monitoring is possible only in reference hospitals. Therefore, the aim of the study was to find simple hematologic indices available from whole blood count 
to help in immunosuppressive therapy monitoring - even in outpatient clinics without specialistic laboratory support.

Neutrophil to lymphocyte ratio (NLR) is a simple marker of inflammatory reactions activation and has been postulated to play a clinical role as a predictive marker in oncology and cardiology [5-9]. The relationship between low values of NLR and rejection episodes in corneal transplantation has already been presented [10]. Park et al. presented evidence of correlation between NLR and overall and graft survival after liver transplantation [11].

Mean platelet volume (MPV) is another parameter representing induction of inflammatory reaction in different clinical situations [12-14]. Platelet indices were linked with worse cardiac function and adverse clinical outcomes in patients with heart failure in the MyoVasc study [15].

The aim of the study was to compare NLR and additionally MPV to tacrolimus serum levels as possible predictors for immunosuppression overdose after heart transplantation.

\section{Material and Method}

We evaluated 30 patients ( 23 men and 7 women) with a mean age of $43 \pm 13$ years who had undergone orthotropic heart transplantation between 2014-2019 in our department. The demographical and clinical data are presented in Table 1.

Table 1. Demographical and clinical data.

\begin{tabular}{cc}
\hline Parameters. & No = 30 \\
\hline Age (years): & $43 \pm 13$ \\
\hline Gender (Male/Female): & $23(77 \%) / 7(23 \%)$ \\
\hline Indication for transplantation: & \\
\hline 1. DCM & $17(57 \%)$ \\
2. ICM HCM & $12(40 \%)$ \\
\hline Concomitant diseases: & $1(3 \%)$ \\
\hline 1. arterial hypertension (\%) & $218 \pm 35$ \\
2. diabetes. mellitus (\%) & \\
\hline 4. hidney dysfunction (\%) & $6(20 \%)$ \\
\hline Postopercholesterolemia (\%) & $3(10 \%)$ \\
\hline Rejection episodes: & 2 \\
\hline 1.within 1st postoperative year & $3(10 \%)$ \\
\hline Imminospitalization (days): & $28 \pm 12$ \\
\hline 1. Tacr + MMF + GS & $2(10 \%)$ \\
2. Tacr + MMF & $0(0 \%)$ \\
\hline
\end{tabular}

Abbreviations: DCM—dilated cardiomyopathy, ICM—ischemic cardiomyopathy, GS—glicocorticosteroids, HCMhyperthrophic cardiomyopathy, MMF-mycophenolate mophetil, Tacr-tacrolimus.

Following the transplantation, the patients were on immunosuppressive therapy, including following protocols of triple therapy with tacrolimus, mycophenolate mophetil, and steroids in $27(90 \%)$ patients and double therapy with tacrolimus and steroids in 2 $(10 \%)$. The mycophenolate mophetil was withdrawn in 2 cases due to gastrointestinal adverse reactions.

\section{Method}

The study period beginning was established as the 12th month after heart transplant and, subsequently, patients were followed up with for 18 months until the 30th month after 
transplant. The blood samples were collected during each outpatient visit between 12th to 30th month post transplantation. NLR and MPV indices were evaluated from whole blood count, as presented in Table 2. Similarly, the tacrolimus C-0 serum levels were measured during outpatient controls performed within 2-month intervals during a total of 18 months of observation (Table 2). The tacrolimus serum C-0 dose recommended for the analyzed treatment period was within the range of $5-15 \mathrm{ng} / \mathrm{mL}$.

Patients with concomitant infection were excluded from the study.

Table 2. Immunosuppressive drug serum levels and NLR and MPV throughout the observation period.

\begin{tabular}{lccc}
\hline \multicolumn{1}{c}{ Intervals } & $\begin{array}{c}\text { Tacrolimus } \\
\text { (Median; Q1-Q3) }\end{array}$ & $\begin{array}{c}\text { NLR } \\
\text { (Median; Q1-Q3) }\end{array}$ & $\begin{array}{c}\text { MPV } \\
\text { (Median; Q1-Q3) }\end{array}$ \\
\hline Time after heart transplantation: & & & \\
\hline - 14 months (median; Q1-Q3) & $9.7(8.4-13.3)$ & $2.11(1.60-3.39)$ & $8.7(7.7-9.1)$ \\
\hline - 16 months (median; Q1-Q3) & $9.3(7.4-13)$ & $2.17(1.61-3.39)$ & $8.6(7.7-9.1)$ \\
\hline - 18 months (median; Q1-Q3) & $9.8(7.5-12.2)$ & $2.70(2.16-3.71)$ & $8.8(7.9-9.4)$ \\
\hline - 20 months (median; Q1-Q3) & $9.1(7.5-12.2)$ & $2.57(1.99-5.04)$ & $8.6(7.8-9.1)$ \\
\hline - 22 months (median; Q1-Q3) & $10.8(7.7-12.8)$ & $2.57(2.04-3.83)$ & $8.5(7.6-9.1)$ \\
\hline - 24 months (median; Q1-Q3) $\quad$ 26 months (median; Q1-Q3) & $10.1(8.6-13.3)$ & $2.27(1.90-3.93)$ & $7.9(7.4-8.9)$ \\
\hline - 28 months (median; Q1-Q3) & $10.1(7.6-15.1)$ & $2.46(1.74-3.91)$ & $8(7.4-9.3)$ \\
\hline - 30 months (median; Q1-Q3) & $9.1(7.9-13.3)$ & $2.31(1.92-4.46)$ & $7.9(7.3-8.9)$ \\
\hline
\end{tabular}

Abbreviations: MPV—mean platelet volume, NLR—neutrophil-to-lymphocyte ratio.

\section{Results}

The separate measurements (18 months of time) were collected, totaling 300 tests in total. The tacrolimus (FK506) and mycophenolate mophetil serum levels were collected as C-0 levels (serum concentration before morning dose of drug administration). During the study period, patients were on low doses of steroid therapy, including $5+/-2.5 \mathrm{mg}$ of prednisolone daily. Mycophenolate mophetil serum C-0 levels were estimated as $2.9+/-$ $0.3 \mathrm{mcg} / \mathrm{mL}$.

There were neither episodes of death nor rejection during the analyzed study period.

The NLR and MPV values were calculated from each whoule blood count. Then, both indices were correlated with Tacrolimus C-0 serum levels. The cutoff point for Tacrolimus was $15 \mathrm{ng} / \mathrm{mL}$ as upper threshold for C-0 concentration. There was one sample with a value of $15 \mathrm{ng} / \mathrm{mL}$ that was excluded from the analysis. There were 48 positive samples for Tacr concentration above $15 \mathrm{ng} / \mathrm{mL}$ and 241 more representing the Tacr serum levels below the cutoff point. The median values of Tacr were $17.6(16.1-20.1)$ vs. $9(7.5-11.3)(p<0.01)$, respectively. The NLR values for Tacr above and below $15 \mathrm{ng} / \mathrm{mL}$ were 3.62 (2.12-16.83) vs. 2.41 (1.81-3.75) $(p=0.001)$, respectively. The MPV values for Tacr above and below $15 \mathrm{ng} / \mathrm{mL}$ were 8.1 (7.7-9.6) vs. 8.4 (7.6-9.2), $p=<0.01$, respectively.

There was a significant correlation between Tacrolimus overdose $(>15 \mathrm{ng} / \mathrm{mL})$, NLR (Spearman's rho 0.99, $p<0.001$ ), and MPV (Spearman's rho 0.989, $p<0.001$ ) values, as presented in Figures 1 and 2. 


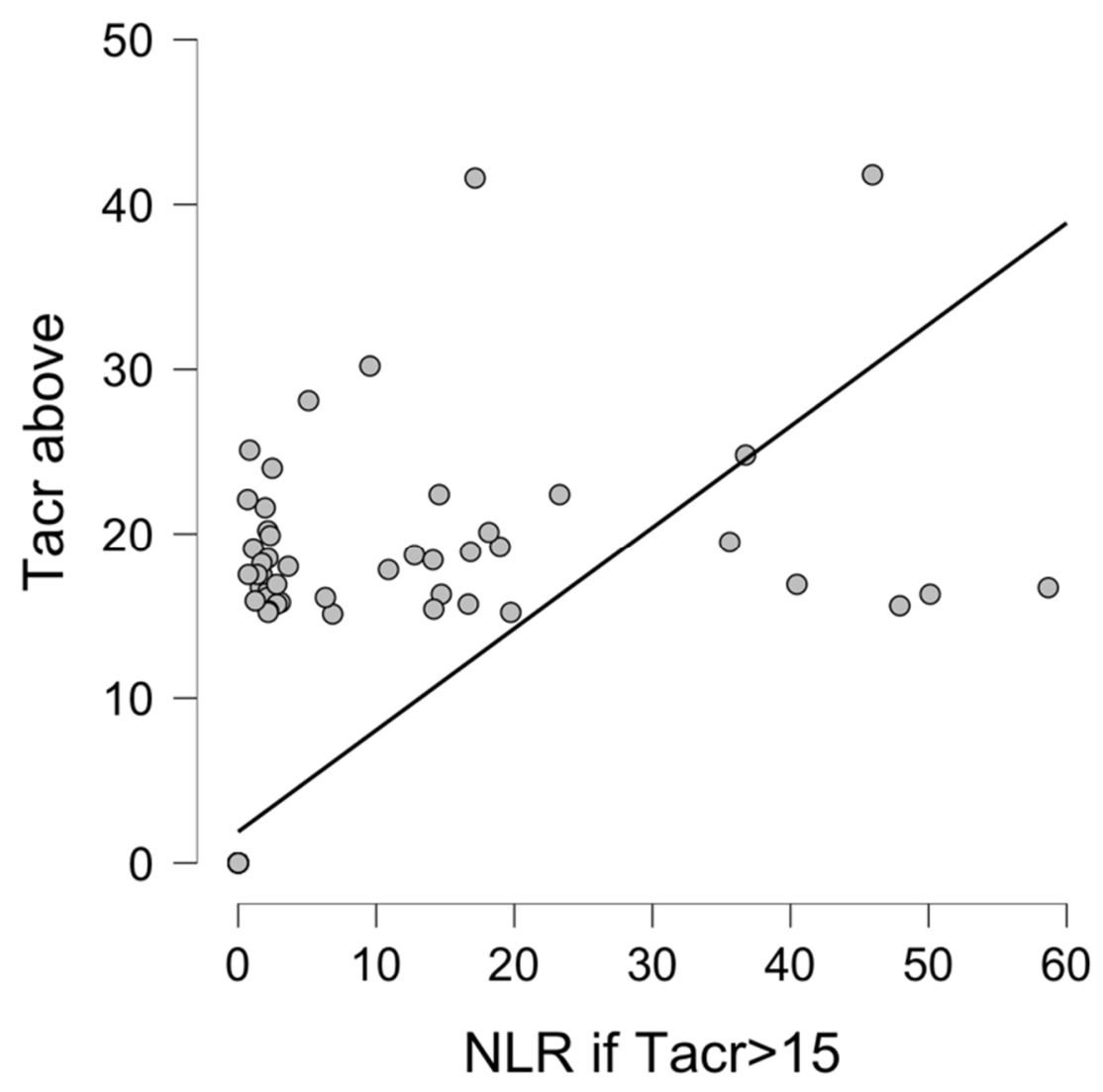

Figure 1. NLR if Tacrolimus C-0 serum level above $15 \mathrm{ng} / \mathrm{mL}$. Correlation between NLR and Tacrolimus overdose (Tacr serum level $>15 \mathrm{ng} / \mathrm{mL}$ ). Abbreviations: NLR—neutrophil-to-lymphocyte ratio, Tacr-tacrolimus.

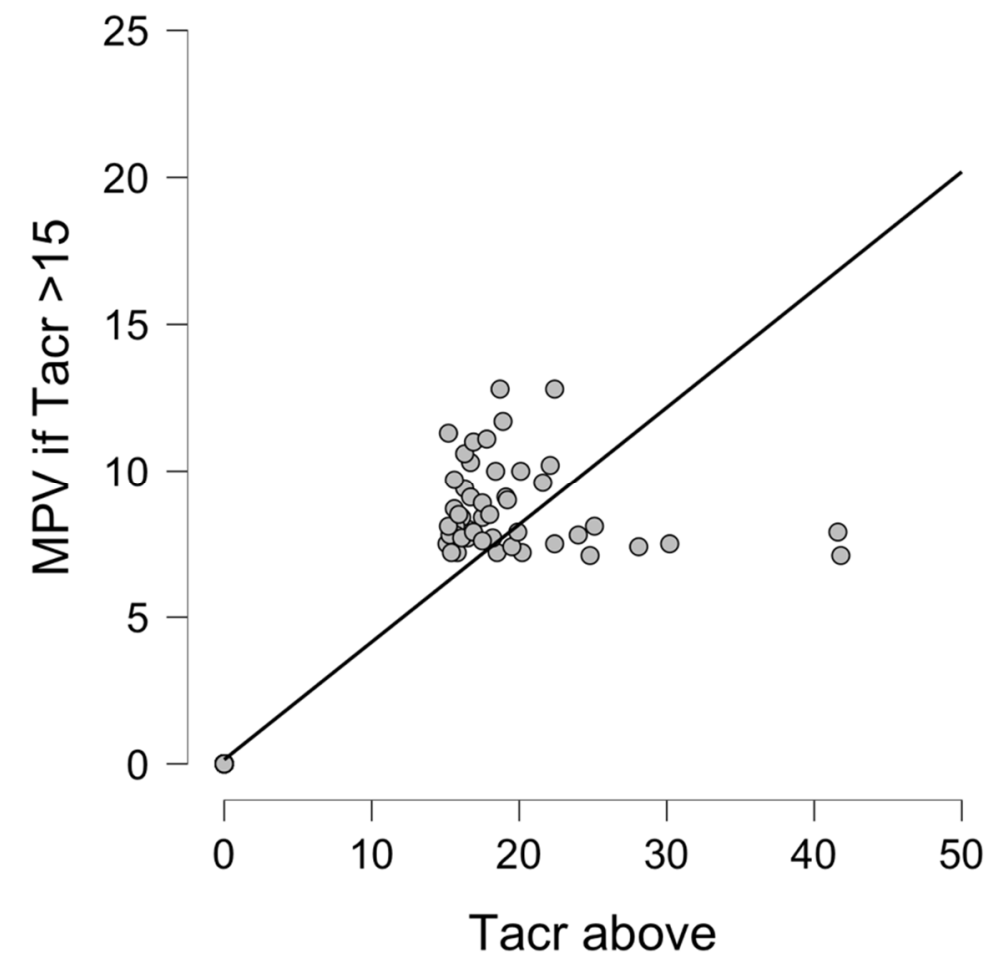

Figure 2. Correlation between MPV and Tacrolimus overdose (Tacr serum level > $15 \mathrm{ng} / \mathrm{mL}$ ). Abbreviations: MPV—-mean platelet volume, Tacr-tacrolimus. 
We also performed receiver operator characteristic (ROC) analysis confirming the relation between NLR and Tacrolimus overdose as presented in Figure 3. The ROC analysis for NLR above 3.62 shows predictive properties for Tacrolimus overdose (over $15 \mathrm{ng} / \mathrm{mL}$ ) (AUC $=0.633, p=0.008$ ) yielding a sensitivity of $50 \%$ and specificity of $83.73 \%$.

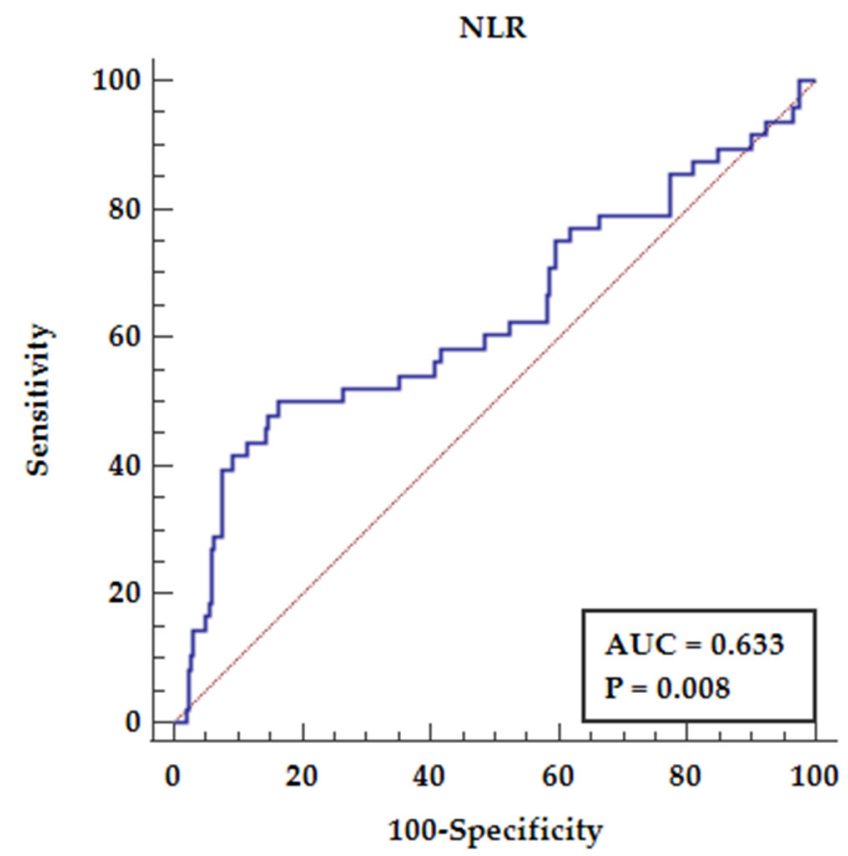

Figure 3. Receiver operator characteristics for NLR and tacrolimus overdose ( $>15 \mathrm{ng} / \mathrm{mL})$. The ROC curve analysis of the NLR for predicting tacrolimus overdose. Abbreviations: NLR—neutrophil to lymphocyte ratio.

The ROC analysis for MPV above 9.9 revealed predictive properties for Tacrolimus overdose (over $15 \mathrm{ng} / \mathrm{mL}$ ) (AUC $=0.527, p=0.564$ ) yielding sensitivity $22.92 \%$ and specificity $91.27 \%$.

\section{Discussion}

The tacrolimus is a crucial component of antirejection therapy after heart transplantation due to superior results in outcomes, as compared to cyclosporine [16]. Immunosuppressant drugs may cause many side effects, including kidney dysfunction, hypertension, post-transplant diabetes mellitus, increased infection risk, and hyperlipidemia, which highlights the importance of individualized therapy [17].

Triple therapy, including calcineurin inhibitor (CNI) and mycophenolate mofetil with corticosteroids, is still the gold antirejection therapy standard. Interactions between aforementioned drugs were postulated. The coadministration of calcineurin inhibitors with mycophenolate mophetil (a prodrug) may be influenced by its enterohepatic recirculation, which allows the former to be converted into an active drug [18]. These factors illustrate the significance of proper dosages of drugs that are monitored by serum levels in specialized centers. These factors are among the most crucial, since they may influence drug serum levels and cause difficulties in proper drug dosing. Additionally, that serum level monitoring is performed only in highly specialized centers. Personalized monitoring is important to control drug dosages and minimize the risk of overdose and drug toxicity.

Variability in serum calcineurin inhibitor levels were presented by Verdu et al. [19]. Drug overdose was related to acute kidney injury in multivariable analyses performed in 107 patients by Pembele et al. [20].

Our study was focused on simple whole blood parameters which could indicate drug overdose and suggest the necessity for more detailed testing in reference centers. Since immunosuppression therapy after heart transplantation in based on calcineurin inhibitor 
(CNI based therapy), we believed that close monitoring would prove crucial for efficient treatment of heart transplant recipients. We found a relationship between CNI overdose and NLR that could be easily monitored, reducing the risk for side effect occurrence in populations of heart transplant recipients. To our best knowledge, this was the first study to present a relationship between simple hematologic indices and tacrolimus serum levels that could enable personalized therapy after heart transplantation.

Neutrophil-to-lymphocyte ratio is a simple parameter, obtained from whole blood count, that describes inflammatory states with possible clinical significance [21,22]. Its significant values for risk of atherosclerosis progression were previously reported [23-25].

Immunosuppressive agents applied in solid organ transplantation significantly reduce rejection rates but fail to control inflammatory reactions related to innate immunity [26]. The novelty of our study lay in the presentation of evidence showing that tacrolimus overdose may be related to NLR increase as shown in innate immunological response overreaction. The results of Shao et al. revealed that calcineurin inhibitor FK506 (tacrolimus) controlled allograft immunity directly through control of T cell immunity, independent of myeloid innate immune cells. The results gave a new perspective on innate immunity control, at least with the utility of such a simple marker as NLR. Moreover, the increase of NLR in our study, correlated with tacrolimus overdose, may indicate innate immunology response activation, while immunosuppressants accumulate in excess doses.

Our study not only pointed out the relationship between tacrolimus overdose and NLR increase, but may also indicate innate immunity reactions due to drug accumulation.

The second parameter that we took into consideration was mean platelet volume (MPV). Platelets play an important role as mediators of inflammation, including their interaction with leucocytes [15]. Therefore, platelet indices have been investigated in clinical conditions related to inflammatory response. The MPV prognostic value in chronic lymphocytic leukemia was shown by Masternak et al. [27]. Cardiovascular risk prognosis related to MPV values was postulated by Crafa et al. [28]. Hepatocellular carcinoma recurrence after liver transplantation predicted by MPV was proven by Zhang et al. [29]. In our study, the higher MPV was related to higher tacrolimus serum levels. While we presented higher NLR reflecting inflammatory response related to tacrolimus overdose, higher MPV may result from the aforementioned platelet-to-leucocytes interaction. According to the meta-analysis conducted by Tullavardana et al., mean platelet volume (MVP) was a potential biomarker for the diagnosis of acute states, including appendicitis [30]. Meyer et al., in their study, presented inflammatory cascade induction via NF-kB9 (nuclear factor kappa-light-chainenhancer of activated B cells), signaling endothelial colony progenitor cells induced by tacrolimus [31].

We believe that the results of our study, despite many limitations, may point to a new perspective for heart recipient monitoring, especially in outpatient clinics in which measuring immunosuppressive drug serum levels is not feasible. Simple blood parameters may help clinicians to detect a risk of tacrolimus overdose and take further steps in certain situations. This is especially true for long-term follow ups, when contact with reference hospitals is infrequent.

\section{Study Limitation}

This was a single-center retrospective study, and can be regarded as the initial report. As such, further studies are required.

\section{Conclusions}

Our results suggested that NLR above 3.62 could be regarded as a simple indicator of tacrolimus overdose in an outpatient clinic.

Author Contributions: Conceptualization, T.U. and A.O.-W.; methodology, T.U. and A.O.-W.; software, M.M.; validation, M.M., T.U. and A.O.-W.; formal analysis, M.M.; investigation, M.R. and A.W.; resources, T.U., A.O.-W., M.R. and A.W.; data curation, T.U. and M.M.; writing-original draft preparation, T.U.; writing—review and editing, A.O.-W., E.S.-M., M.J. and B.P.; visualization, T.U. 
and A.O.-W.; supervision, M.J.; project administration, T.U.; funding acquisition, B.P. and M.J. All authors have read and agreed to the published version of the manuscript.

Funding: This research received no external funding.

Institutional Review Board Statement: The study was conducted according to the guidelines of the Declaration of Helsinki and approved by the Institutional Ethics Committee of Poznan University of Medical Sciences (protocol code 912/21 from 24 November 2021).

Informed Consent Statement: Informed consent was obtained from all subjects involved in the study.

Data Availability Statement: Data supporting reported results can be found by direct contact with corresponding author after justifiable explanation of requirements for 3 years following the publication.

Conflicts of Interest: The authors declare no conflict of interest.

\section{References}

1. Roger, V.L. Epidemiology of Heart Failure: A Contemporary Perspective. Circ. Res. 2021, 128, 1421-1434. [CrossRef]

2. Crespo-Leiro, M.G.; Barge-Caballero, E. Advanced Heart Failure: Definition, Epidemiology, and Clinical Course. Heart Fail. Clin. 2021, 17, 533-545. [CrossRef]

3. Sutaria, N.; Sylvia, L.; DeNofrio, D. Immunosuppression and Heart Transplantation. Handb. Exp. Pharmacol. 2021. Epub ahead of print. [CrossRef]

4. Hussain, T.; Nassetta, K.; O'Dwyer, L.C.; Wilcox, J.E.; Badawy, S.M. Adherence to immunosuppression in adult heart transplant recipients: A systematic review. Transpl. Rev. 2021, 35, 100651-100658. [CrossRef] [PubMed]

5. Sanna, E.; Tanca, L.; Cherchi, C.; Gramignano, G.; Oppi, S.; Chiai, M.G.; Macciò, A.; Madeddu, C. Decrease in Neu-trophil-toLymphocyte Ratio during Neoadjuvant Chemotherapy as a Predictive and Prognostic Marker in Advanced Ovarian Cancer. Diagnostics 2021, 11, 1298. [CrossRef] [PubMed]

6. Ustuntas, G.; Basat, S.; Calik, A.N.; Sivritepe, R.; Basat, O. Relationship Between Epicardial Fat Tissue Thickness and CRP And Neutrophil Lymphocyte Ratio in Metabolic Syndrome Patients over 65 Years. SiSli Etfal Häst. Tip Bulteni/Med. Bull. Sisli Etfal Hosp. 2021, 55, 405. [CrossRef] [PubMed]

7. Ji, Z.; Liu, G.; Guo, J.; Zhang, R.; Su, Y.; Carvalho, A.; Qu, Y.; Zuo, W.; Yao, Y.; Lin, J.; et al. The Neutro-phil-to-Lymphocyte Ratio Is an Important Indicator Predicting In-Hospital Death in AMI Patients. Front. Cardiovasc. Med. 2021, 8, 706852-706861. [CrossRef]

8. Urbanowicz, T.; Michalak, M.; Gąsecka, A.; Perek, B.; Rodzki, M.; Bociański, M.; Straburzyńska-Migaj, E.; Jemielity, M. Postoperative Neutrophil to Lymphocyte Ratio as an Overall Mortality Midterm Prognostic Factor fol-lowing OPCAB Procedures. Clin. Pract. 2021, 11, 587-597. [CrossRef]

9. Agarwal, R.; Aurora, R.G.; Siswanto, B.B.; Muliawan, H.S. The prognostic value of neutrophil-to-lymphocyte ratio across all stages of coronary artery disease. Coron. Artery Dis. 2021. [CrossRef]

10. Yıldız, M.B.; Yıldız, E. Evaluation of serum neutrophil-to-lymphocyte ratio in corneal graft rejection after low-risk penetrating keratoplasty. Int. Ophthalmol. 2021, 1-7. [CrossRef]

11. Park, J.; Lee, S.H.; Gwak, M.S.; Ko, J.S.; Han, S.; Choi, G.S.; Joh, J.W.; Kim, J.; Kim, G.S. Association between neutro-phillymphocyte ratio change during living donor liver transplantation and graft survival. Sci. Rep. 2021, 11, 4199-4209. [CrossRef] [PubMed]

12. Boyuk, F. The role of the multi-inflammatory index as a novel inflammation-related index in the differential diagnosis of massive and non-massive pulmonary embolism. Int. J. Clin. Pr. 2021, e14966. [CrossRef] [PubMed]

13. Varman, A.; Alkan, S. Evaluation of neutrophil/lymphocyte ratio, platelet/lymphocyte ratio, mean platelet volume, and neutrophil/monocyte ratio in patients with benign breast lesions. Bratisl. Lek. Listy 2021, 122, 489-492. [CrossRef] [PubMed]

14. Atwa, E.T.; Omar, H.M.; Amin, A.; Hammad, M. Red Cell Distribution Width and Mean Platelet Volume in Rheumatoid Arthritis Patients: Its Association with Disease Activity. Reumatol. Clin. 2021, S1699-S1709. [CrossRef] [PubMed]

15. Dahlen, B.; Schulz, A.; Göbel, S.; Tröbs, S.; Schwuchow-Thonke, S.; Spronk, H.M.; Prochaska, J.H.; Arnold, N.; Lackner, K.J.; Gori, T.; et al. The impact of platelet indices on clinical outcome in heart failure: Results from the MyoVasc study. ESC Hear. Fail. 2021, 8, 2991-3001. [CrossRef]

16. Krisl, A.; Stampf, S.; Hauri, D.; Binet, I.; Mueller, T.; Sidler, D.; Hadaya, K.; Golshayan, D.; Pascual, M.; Koller, M.; et al. The Swiss Transplant Cohort Study Stcs. Immunosuppression management in renal trans-plant recipients with normal-immunological risk: 10-year results from the Swiss Transplant Cohort Study. Swiss Med. Wkly. 2020, 150, 20354-20364.

17. Parlakpinar, H.; Gunata, M. Transplantation and immunosuppression: A review of novel transplant-related immunosuppressant drugs. Immunopharmacol. Immunotoxicol. 2021, 43, 651-665. [CrossRef]

18. van Gelder, T. How cyclosporine reduces mycophenolic acid exposure by $40 \%$ while other calcineurin inhib-itors do not. Kidney Int. 2021, S0085, 262-270.

19. Verdú, L.S.; García-Romero, E.; Díez-López, C. Clinical impact of variability in blood concentrations of calcineurin inhibitors in heart transplant: A double-edged sword. Rev. Esp. Cardiol. 2021, S1885, 262-270. 
20. M'Pembele, R.; Roth, S.; Stroda, A.; Lurati Buse, G.; Sixt, S.U.; Westenfeld, R.; Polzin, A.; Rellecke, P.; Tudorache, I.; Hollmann, M.W.; et al. Risk Factors for Acute Kidney Injury Requiring Renal Replacement Therapy after Orthotopic Heart Transplantation in Patients with Pre-served Renal Function. J. Clin. Med. 2021, 10, 4117. [CrossRef]

21. Xue, J.; Ma, D.; Jiang, J.; Liu, Y. Diagnostic and Prognostic Value of Immune/Inflammation Biomarkers for Ve-nous Thromboembolism: Is It Reliable for Clinical Practice? J. Inflamm. Res. 2021, 14, 5059-5077. [CrossRef]

22. Wang, H.; Liu, Y.; Zhao, J.; Guo, X.; Hu, M.; Chen, Y. Possible inflammatory mechanisms and predictors of Park-inson's disease patients with fatigue (Brief Review). Clin. Neurol. Neurosurg. 2021, 208, 106844-106851. [CrossRef]

23. Li, X.; Li, J.; Wu, G. Relationship of Neutrophil-to-Lymphocyte Ratio with Carotid Plaque Vulnerability and Occurrence of Vulnerable Carotid Plaque in Patients with Acute Ischemic Stroke. BioMed Res. Int. 2021, 2021, 6894623. [CrossRef]

24. Chistiakov, D.A.; Kashirskikh, D.A.; Khotina, V.A.; Grechko, A.V.; Orekhov, A.N. Immune-Inflammatory Responses in Atherosclerosis: The Role of Myeloid Cells. J. Clin. Med. 2019, 8, 1798. [CrossRef] [PubMed]

25. Neupane, R.; Jin, X.; Sasaki, T.; Li, X.; Murohara, T.; Cheng, X.W. Immune Disorder in Atherosclerotic Cardiovascular DiseaseClinical Implications of Using Circulating T-Cell Subsets as Biomarkers. Circ. J. 2019, 83, 1431-1438. [CrossRef] [PubMed]

26. Graham, M.L.; Ramachandran, S.; Singh, A.; Moore, M.E.G.; Flanagan, E.B.; Azimzadeh, A.; Burlak, C.; Mueller, K.R.; Martins, K.; Anazawa, T.; et al. Clinically available immunosuppression averts rejection but not systemic inflammation after porcine islet xenotransplant in cynomolgus macaques. Arab. Archaeol. Epigr. 2021. [CrossRef]

27. Masternak, M.; Puła, B.; Knap, J.; Waszczuk-Gajda, A.; Drozd-Sokołowska, J.; Wdowiak, K.; Grosicki, S.; Kozłowska, I.; Kaźmierczak, M.; Łabędź, A.; et al. Mean Platelet Volume Has Prognostic Value in Chronic Lymphocytic Leukemia. Cancer Manag. Res. 2020, 12, 9977-9985. [CrossRef] [PubMed]

28. Crafa, A.; Condorelli, R.A.; Mongiò̀, L.M.; Cannarella, R.; Barbagallo, F.; Aversa, A.; Izzo, G.; Perri, A.; Calogero, A.E.; La Vignera, S. Mean Platelet Volume as a Marker of Vasculogenic Erectile Dysfunction and Future Cardio-vascular Risk. J. Clin. Med. 2020, 9, 2513. [CrossRef]

29. Zhang, A.-B.; Zhang, Z.-H.; Zhang, J.; Lin, B.-Y.; Geng, L.; Yang, Z.; Feng, X.-N.; Zheng, S.-S. Lower mean platelet volume is a risk indicator of hepatocellular carcinoma recurrence following liver transplantation. Hepatobiliary Pancreat. Dis. Int. 2019, 18, $223-227$. [CrossRef]

30. Tullavardhana, T.; Sanguanlosit, S.; Chartkitchareon, A. Role of platelet indices as a biomarker for the diagno-sis of acute appendicitis and as a predictor of complicated appendicitis: A meta-analysis. Ann. Med. Surg. 2021, 66, 102448-102455. [CrossRef]

31. Shao, K.; Lu, Y.; Wang, J.; Chen, X.; Zhang, Z.; Wang, X.; Yang, H.; Liu, G. Different Effects of Tacrolimus on Innate and Adaptive Immune Cells in the Allograft Transplantation. Scand. J. Immunol. 2016, 83, 119-127. [CrossRef] [PubMed] 